\title{
Indication and Technical Aspects of Adrenal Blood Sampling
}

\section{Indikationen und Technik der selektiven Nebennierenvenen- blutentnahme}

Authors

Affiliations
D. Blondin ${ }^{1,2}$, I. Quack³ ${ }^{3}$ M. Haase ${ }^{4}$, S. Kücükköylü ${ }^{3}$, H. S. Willenberg ${ }^{4}$

Department of Radiology, Medical Faculty HHU, Düsseldorf

2 Department of Radiology and Nuclear Medicine, Städtische Kliniken Mönchengladbach

3 Department of Nephrology, University Hospital Düsseldorf, Medical Faculty HHU, Düsseldorf

${ }^{4}$ Department of Endocrinology and Diabetology, University Hospital Düsseldorf, Medical Faculty HHU, Düsseldorf
Key words

- abdomen

- adrenal gland

- angiography

- endocrine disorders

received $\quad 10.2 .2014$

accepted 23.7.2014

Bibliography

Dol http://dx.doi.org/

10.1055/s-0034-1385081

Published online: 16.9.2014

Fortschr Röntgenstr 2015; 187 :

19-28 @ Georg Thieme Verlag

KG Stuttgart - New York ·

ISSN 1438-9029

\section{Correspondence}

\section{Prof. Dirk Blondin}

Klinik für Radiologie, Gefäßradiologie und

Nuklearmedizin, Städtische Kliniken Mönchengladbach

GmbH Elisabeth-Krankenhaus Rheydt

Hubertusstraße 100

41239 Mönchengladbach Germany

Tel.: ++49/2166/3942170

Fax: ++49/2166/39427 70

dirk.blondin@sk-mg.de

\section{Abstract}

$\nabla$

Adrenal disorders are relative frequent with regard to the incidence of adrenal tumors and the high portion in causes of secondary hypertension. Morphological changes in the adrenal glands can lead to very different functional disorders that may be clinically overt or hard to diagnose. On the other hand, they can already be functionally relevant when structural changes are too small to be picked up by imaging. Adrenal venous sampling serves to determine the source of hormone excess through the analysis of adrenal blood. In this manuscript, we call attention to the clinical backgrounds, critical points in praxis, technical aspects and developments in the the field of adrenal venous sampling. The consideration of these important points in the clincal setting may make adrenal vein sampling studies sucessful and help to select patients that qualify for adrenalectomy.

Key Points:

- Selective adrenal venous sampling (AVS) currently continues to be the gold standard for localization diagnostics in patients with primary hyperaldosteronism.

- Comprehensive standardization of all preceding examinations and AVS is necessary to ensure high success rates.

- The method is supported by contrast-enhanced imaging for ensuring proper positioning of the catheter in the adrenal veins and the rapid cortisol assay.

- Knowledge of the anatomy and normal variants of the adrenal veins facilitates adrenal venous sampling.

Citation Format:

- Blondin D, Quack I, Haase M et al. Indication and Technical Aspects of Adrenal Blood Sampling. Fortschr Röntgenstr 2015; 187: 19-28

\section{Zusammenfassung \\ $\nabla$}

Nebennierenerkrankungen sind unter Berücksichtigung der Inzidenzen von Nebennierentumoren und hormonellen Ursachen als prävalenteste sekundäre Hypertonieformen relativ häufig. Morphologische Veränderungen der Nebennieren können zu ganz unterschiedlichen sichtbaren oder kaum messbaren Funktionsstörungen führen. Andererseits können sich Funktionsstörungen klinisch bereits bemerkbar machen, wenn strukturelle Veränderungen der Nebennieren in der Schnittbildgebung noch nicht erfasst werden. Der selektive Nebennierenvenenkatheter dient der Gewinnung adrenalen Blutes, um die Quelle eines Hormonexzesses zu identifizieren. In dieser Arbeit wird auf Hintergründe, Fallstricke, technische Aspekte und Entwicklungen der Nebennierenvenenkatheterdiagnostik eingegangen. Deren Beachtung in der klinischen Praxis kann die Nebennierenvenenblutentnahme zu einer erfolgreichen Prozedur machen und damit helfen, Patienten zu selektieren, die von einer Adrenalektomie profitieren.

\section{Introduction}

$\nabla$

Since evidence of an adrenal tumor does not automatically identify the source of hormone excess, and tomography cannot always pick up small but relevant endocrinal adenomas $(<1 \mathrm{~cm})$, selective adrenal venous sampling (AVS) is the gold standard for the identification of patients with primary aldosteronism who can benefit from adrenalectomy. Removal of the source of verified adrenal hormone excess can result in a cure or significantly improve the prognosis with respect to cardiovascular complications and renal function [1 - 3]. This paper considers disorders in which AVS represents an elementary component of the diagnostics, whereby the focus is on technical 
and clinical aspects the observance of which in clinical practice has contributed to the success of this investigation.

\section{Disorders that can be better characterized using selective adrenal vein catheterization}

\section{Primary aldosteronism (Conn's syndrome, PA)}

Primary aldosteronism (PA), with a prevalence of $5-10 \%$ is the most frequent secondary form of hypertension [4-6]. PA is particularly frequent $(10-20 \%)$ in patients with difficult to manage hypertension, making up approximately $10-30 \%$ of patients with high blood pressure [7]. The possibility of Conn's syndrome should be excluded for those patients for whom renal nerve ablation is considered. Primary aldosteronism does not exhibit a homogeneous disease pattern. In addition to various familiar forms, recently several somatic mutations have been discovered that contribute to the development of this disorder [8-11]. Further, the differentiation of unilateral from bilateral disease is of particular clinical significance due to the related therapeutic options. It should be presumed a diagnosis of bilateral hyperplasia (BAH) is provided in approximately $50 \%$ of patients, whereas in the remaining cases an aldosteroneproducing adenoma (APA) and asymmetrical aldosterone excess is present. Rarer entities include adrenal cortex carcinoma, which occurs in $<1 \%$ of cases $[12,13]$.

Patients with Conn's syndrome have a significantly increased risk of cardiac and vascular diseases, even when compared with patients with similarly poor blood pressure values, but without hyperaldosteronism $[14,15]$. Therefore is it worthwhile for those affected patients to follow the route of multi-step diagnosis consisting of screening examinations, functional tests, imaging and successful adrenal venous catheterization [16-18]. This is reflected in an elevated aldosterone to renin ratio, which is also appropriate as a screening examination as long as no anti-hypertensive medications have been taken, as these intervene in the renin-angiotensin system ( $\bullet$ Fig. 1 ); such an examination should take into account cyclical phases and exclude as well other bases for a false positive laboratory result such as hyperkalemia, infection, stress, etc.

If the renin level is low while aldosterone is inadequately high (e. g. $>20 \mu \mathrm{g} / \mathrm{l}: \mu \mathrm{g} / \mathrm{l}$ ), a confirmation test must be performed due to the limited specificity of the screening examinations [16]. The sodium chloride load test and fludrocortisone suppression test are primarily suitable for this purpose. However, since the tests demonstrate sensitivity and specificity between $80 \%$ and $90 \%$ [16], other aspects such as a typical history, concomitant medication during the test, or hypokalemia (in free-flowing blood) must be taken into account. Since the fludrocortisone suppression test appears to provide better sensitivity and produces fewer false negative results, in cases of doubt results of this test should be given more weight than those of others [19,20]. If the diagnosis has confirmed Conn's syndrome, the next step is investigate which adrenal gland is the source of aldosterone excess [16]. Since the findings of functional diagnostics and imaging too frequently differ, a selective AVS should be performed; this procedure was first described in 1967 [21] and currently represents the gold standard for differentiating various abnormality subtypes [22 - 24].

As a result of a systematic analysis, approx. $37 \%$ of all 950 reported patients would have undergone incorrect treatment if only CT or MRI had been used for localization diagnostics [25]. Of these, about $15 \%$ would have undergone surgery as a consequence, even though bilateral disease was present; $3.9 \%$ would have had surgery on the wrong side, whereas an adrenalectomy would have been withheld for $19 \%$, despite lateralized aldosterone excess. There are various reasons for the limited value of MRI or CT tomography. Hormonally-inactive adrenal masses occur more frequently with increasing age; this has practical importance above the age of 40 . On the other hand, adenomas forming aldosterone are sometimes very small $(<5 \mathrm{~mm})$ and can escape detection [26, 27]. In a collective study,

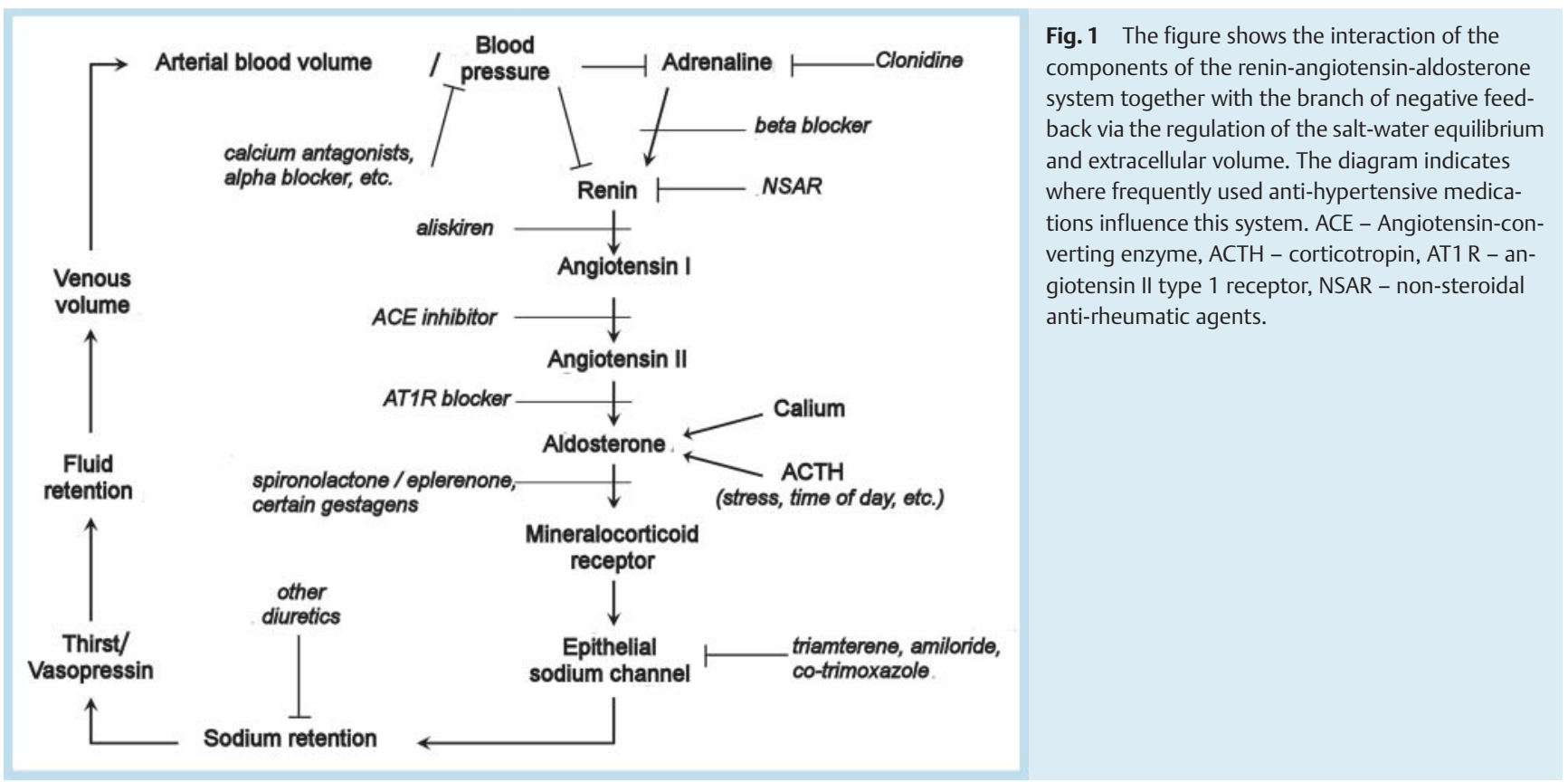


Stowasser et al. found that more than $50 \%$ of aldosteroneproducing adenomas were less than $1 \mathrm{~cm}$ in size [22].

A CT of the adrenal glands is nevertheless useful, as it can rule out adrenal cortex carcinoma while displaying the anatomy of the adrenal veins. Adrenal venous sampling plays a decisive role in the differentiation of the two major entities of Conn's syndrome, aldosterone-producing adenoma (APA) and bilateral hyperplasia (BAH).

\section{Bilateral adrenal tumors, adrenal Cushing's syndrome and other indications}

While aldosterone-producing tumors are sometimes too small to be detected by radiological diagnostics, and there appear to be two seemingly normal, although somewhat hyperplastic adrenal glands in the image, adrenal cortex lesions that are the source of Cushing's syndrome are clearly visible, with few exceptions.

However, time and again, two adrenal tumors occur.

In addition to cortisol-producing adenoma (CPA), manifestations can also include simultaneously present non-hormonally active tumors, pheochromocytomas or ACTH-independent macronodular adrenal hyperplasia (AIMAH, Fig. 2). Whereas in the past, operations were first performed on the side with the visibly larger tumor [28, 29], improved and expanded analytical methods have enabled the use of an adrenal vein catheter to identify the more hormonally productive side as well as hormonal characterization of adrenal cortex tumors [30 - 32].

Cushing's syndrome likewise exhibits a smooth transition from minor symptoms to the well-known clearly visible syndrome, so that multi-stage diagnostics can be utilized employing various medications and synthetic hormones, while taking into account diurnal fluctuations [18]. Further, in cases of Cushing's syndrome (especially in its milder form), it should always be critically considered whether the tested hormone values actually reflect the clinical condition of the patients and their symptoms and whether an operation and interventional investigation will aid in diagnosis. Existing guidelines and recommendations provide practical assistance in this regard $[33,34]$.

An additional option for utilizing AVS is the identification of the source of hyperandrogenemia. Thus in the case of bilat- eral adrenal disorders, an attempt can be made to identify the dominant side. If the ovarial veins are likewise cannulated, then it can investigated whether a small androgen-producing Leydig cell tumor is present, or whether the source is of adrenal origin [35].

For the sake of completeness, it should be mentioned that AVS has also been used to investigate pheochromocytomas. Due to potential hazards, this procedure is being increasingly abandoned.

\section{Adrenal venous sampling technique $\nabla$}

A study by Mulatero et al. showed that aldosterone-producing adenomas are more frequently found in centers where AVS is regularly performed [5]. At $>95 \%$, the sensitivity and specificity of AVS is very high if selective blood sampling succeeds. Even in specialized centers, the technical success rate is only $70-90 \%$; at the lower range the quality is comparable to conventional tomography [36] Due to the diagnostic effort and life-long therapeutic consequences, AVS must therefore be successful, and is a highly important element in the investigation of patients with Conn's syndrome. Beyond that, AVS is also suitable for better characterization of other adrenal disorders.

The prerequisites for a high success rate are the experience of the radiologist as well as good knowledge of anatomy and related standard variations ( $\bullet$ Fig. 3). Selective adrenal blood sampling is frequently viewed as difficult and time consuming due to three different reasons. The first reason is due to the small size of the right adrenal vein; the second is a result of lack of knowledge of angiographic images of adrenal veins and the resulting difficulty in distinguishing other vessels which may lead into the posterior wall of the inferior vena cava (IVC). The third reason is related to the length of the segment of the inferior vena cava which, due to the high variance of adrenal vein anatomy, can extend from the $10^{\text {th }}$ to the $12^{\text {th }}$ intercostal space. To ensure the proper position of the catheter, careful display of the vein should utilize a contrast agent administered via the catheter ( $\bullet$ Fig. 4). Display of the proper catheter position using a C-arm CT is a current additional option. Perfect positioning
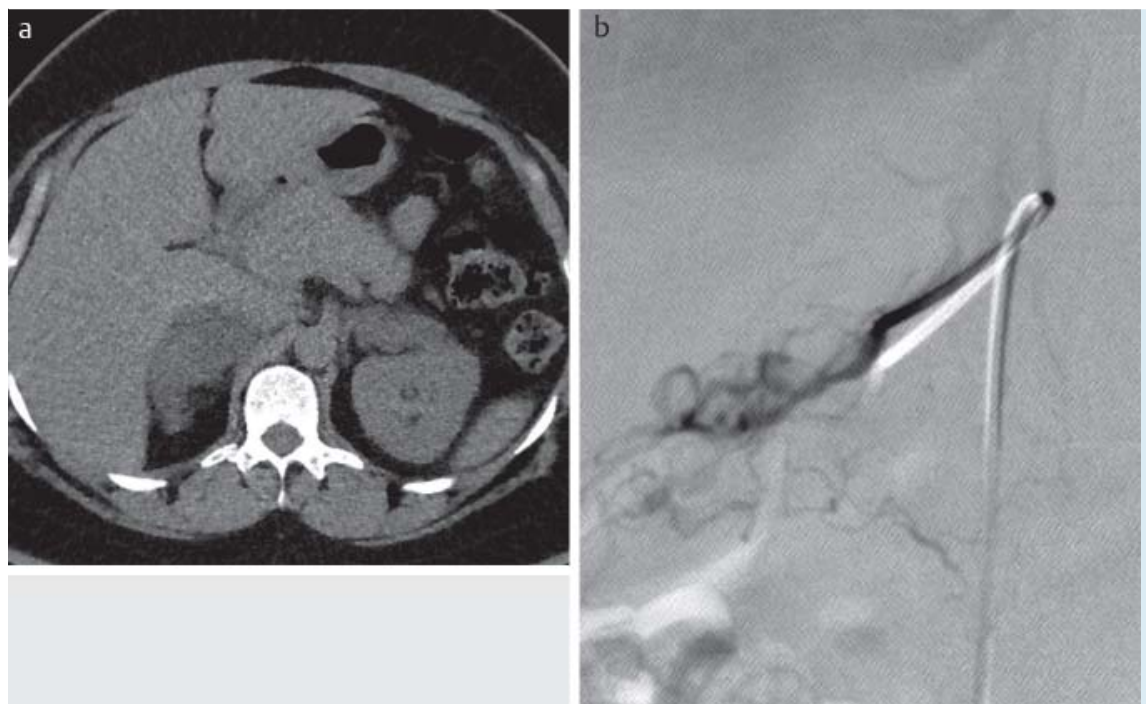

Fig. 2 a Unenhanced $C T$ of the upper abdomen phase of a 44-year-old patient with ACTH-independent macronodular adrenal hyperplasia (AIMAH). b Significant elongation of the exemplified right adrenal veins during AVS. 
should permit selective sampling of the entire adrenal gland; this is difficult, however [37]. It is particularly important to distinguish the right adrenal vein leading directly into the inferior vena cava from small accessory hepatic veins ( $\bullet$ Fig. 5 ).

The earlier method involving blood sampling from the adrenal glands, the IVC above and below the adrenal veins and additional periphery can be abandoned in favor of a simple peripheral control sample obtained via the bleedback prevention valve inserted in the inguinal vein.

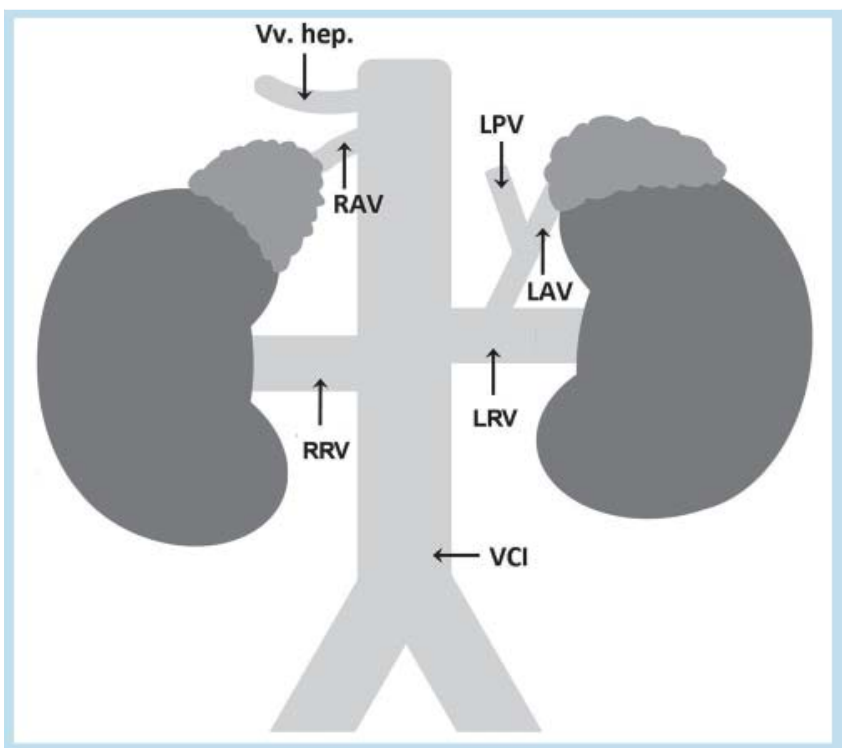

Fig. 3 Sketch of a typical configuration of the adrenal veins. LAV: left adrenal vein, LRV: left renal vein, LPV: left phrenic vein (inferior), RAV: right adrenal vein, RRV: right renal vein, $\mathrm{VCl}$ : vena cava inferior, $\mathrm{V} v$ hep.: hepatic vein(s).

\section{Adrenal gland vein anatomy}

$\nabla$

Venous drainage of the adrenal glands occurs bilaterally via a central vein [38]. Cadaver studies have indicated an average length of $1-15 \mathrm{~mm}$ for the right adrenal vein and $10-$ $40 \mathrm{~mm}$ to the confluence with the phrenic vein for the left adrenal vein [39-41]. The central vein of the right adrenal gland may be duplicated or even tripled, and one of these veins can empty into the inferior phrenic vein or the renal vein, but one vein always leads into the inferior vena cava. Central adrenal gland veins with intrahepatic connections are rare; in the literature the incidence of these variants differ, between $<1-10 \%$. Presumably this phenomenon is seldom encountered [39-42], and there should be no confusion regarding the hepatic juncture of peripheral adrenal veins (see below).

The left central adrenal gland vein generally joins the inferior phrenic vein forming a common trunk of variable length and enters the left renal vein from above [38-40]. Only rarely do the left adrenal gland vein and the inferior phrenic vein drain separately into the renal vein.

Both adrenal glands have capsule veins emanating from the surface which are joined with intercostal or phrenic veins, and - more rarely - with hepatic veins ( 0 Fig. 6 ). On the left side, there may be connections to the (hemi) azygos veins, to the renal vein or the inferior vena cava ( $\bullet$ Fig. 7). Angiographic representation of these superficial veins supports the detection of a proper catheter position.

The anatomical variations of the left renal vein and inferior vena cava are significant for probing the left adrenal vein. These can be identified easily using CT in the venous perfusion phase. This is a relevant argument for performing a CT of the adrenal glands and renal anatomy prior to selective adrenal vein sampling to avoid unexpected difficulties during catheterization and to allow the left adrenal vein to be probed without loss of time.

Using a thin-slice CT (SD $2 \mathrm{~mm}$ ), identification of the right adrenal vein is possible in $50 \%$ of patients. The CT is used to assess the position of the adrenal vein, in the DSA, the outlet for the vein should be considered to be $1-1.5 \mathrm{~cm}$ upward from the position indicated in the CT image. If the
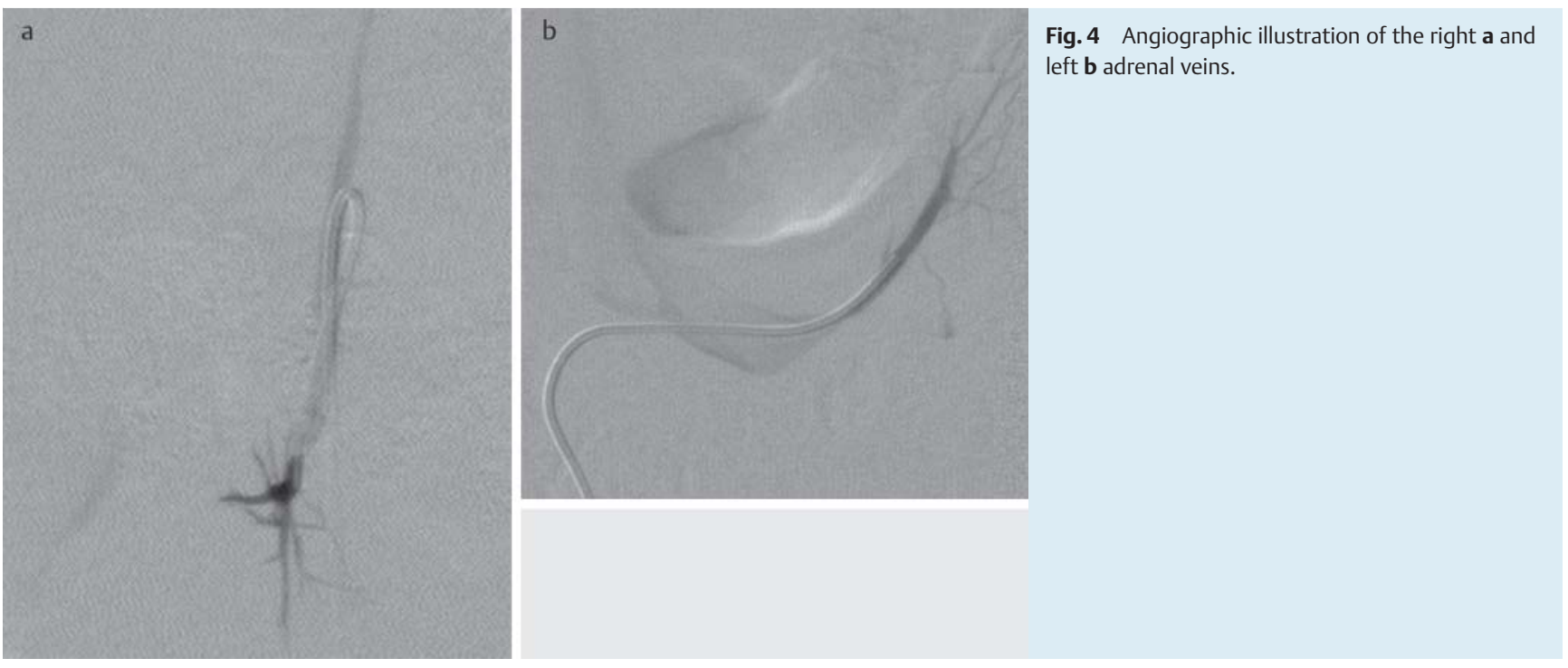

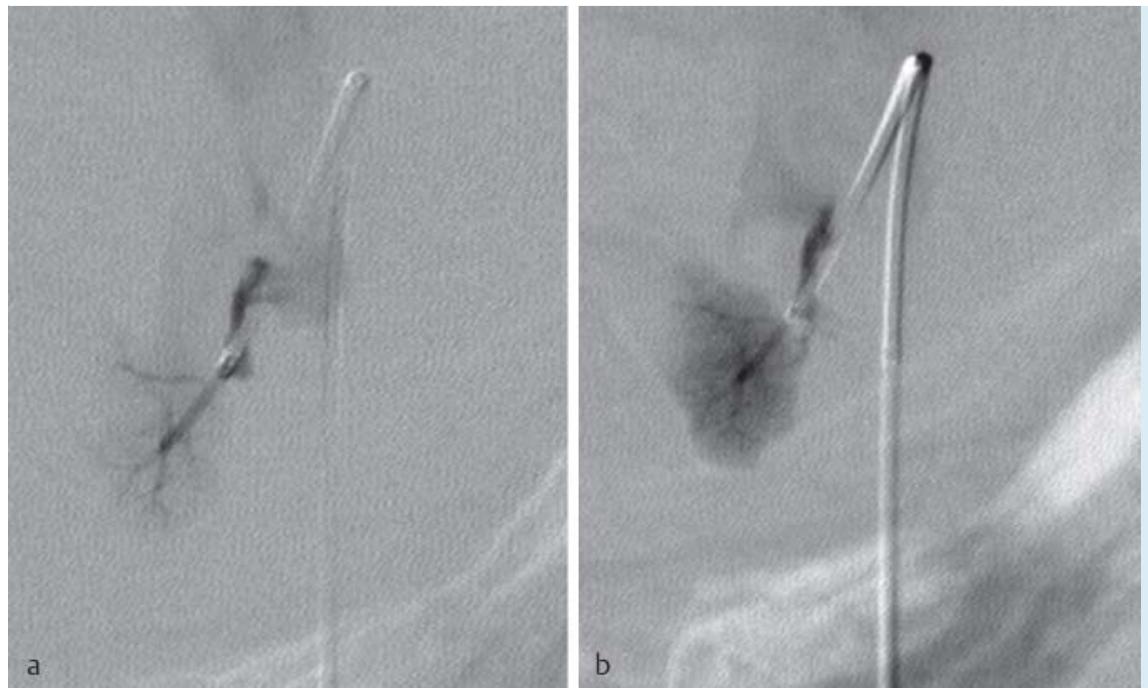

Fig. 5 a, b Illustration of an accessory small hepatic vein; protracted contrast agent administration indicates homogeneous opacification of hepatic parenchyma. In a confusion with the right adrenal gland is possible at first glance.

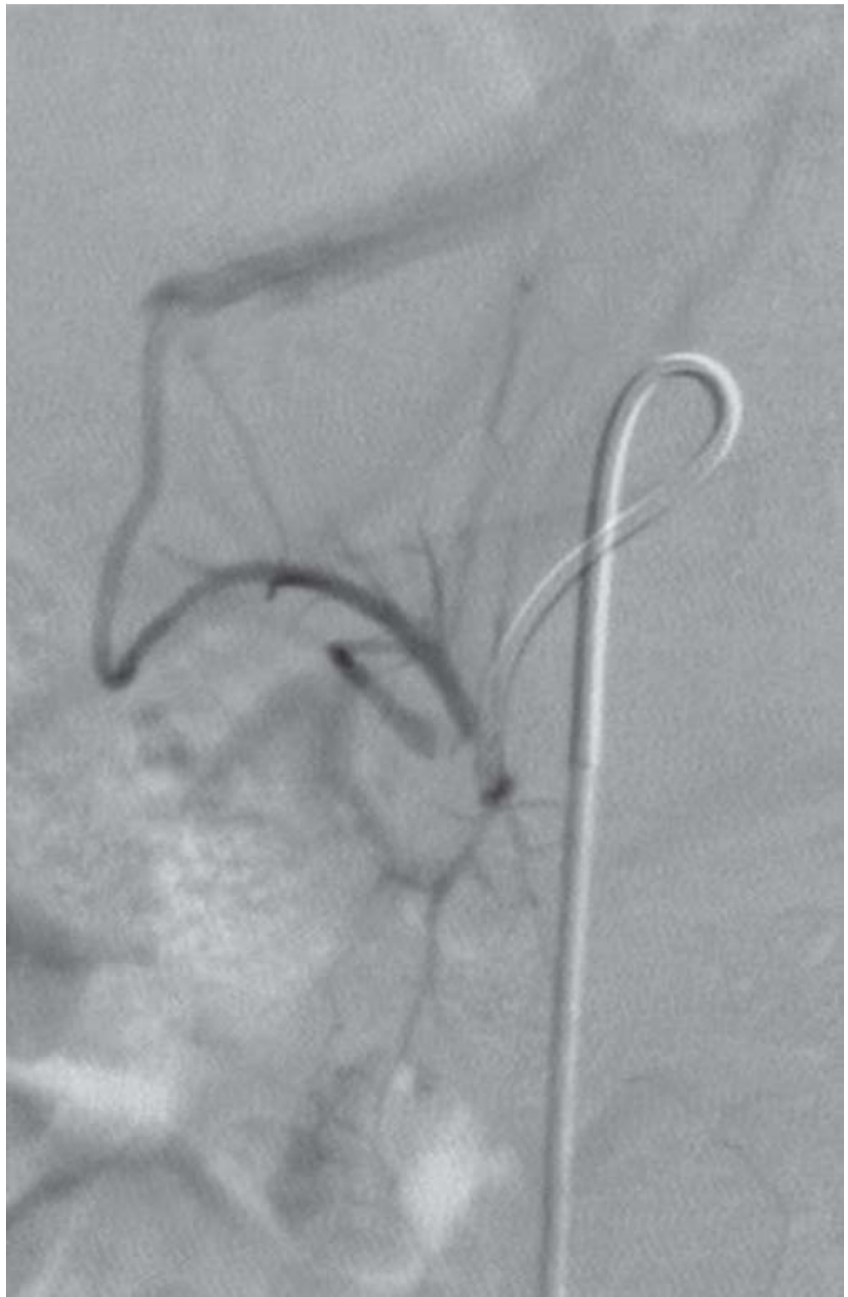

Fig. 6 Juncture of a right-side superficial adrenal vein with intrahepatic veins.

right adrenal vein cannot be differentiated in the $\mathrm{CT}$, the center of the adrenal gland should be used to estimate the position of the vein [43].
Blood vessel imaging of the right adrenal gland shows, in addition to variances, recurrent vascular patterns which are described below.

- The vessel image can be represented glandularly with a central main vessel and several branches, which typically emanate at a $<90^{\circ}$ angle from the trunk $[39,40,42]$ (๑ Fig. 8a).

- The adrenal veins can be arrayed in classic delta form, superficial veins can also be displayed ( $\bullet$ Fig. 8b).

- An angiographic image can display triangularly arranged veins; the branches of the adrenal gland are rather densely delineated in the upper angle.

- Contrast imaging of the adrenal veins can be very subtle, so that a glandular constellation of blood vessels is not recognizable; sometimes only a main trunk and individual superficial veins can be displayed ( $\bullet$ Fig. $8 c$ ).

- The vein formation can be spider-like with a central vein and lateral branches as well as superficial veins reminiscent of a spider ( $\bullet$ Fig. $\mathbf{8 d}$ ).

Differentiation from small accessory hepatic veins can be made by somewhat protracted application of the contrast agent; after a few seconds, liver tissue shows homogeneous contrast ( $\bullet$ Fig. 5 ), whereas the fine branches of the adrenal gland remain, but without planar contrast.

An adenoma can also be differentiated in an image during selective adrenal vein sampling. In the case of apparent hyperplasia of the adrenal glands, the angiographic image will display a corresponding vessel pattern up to elongated veins (o Fig.2).

\section{Catheter material}

$\nabla$

To perform selective adrenal vein sampling, a $6 \mathrm{~F}$ bleedback prevention valve should be inserted inguinally into the femoral vein. The catheter, either $5 \mathrm{~F}$ or $4 \mathrm{~F}$, is inserted into the inferior vena cava up to the height determined in the CT, and rotated dorsally. Probing is performed by arching up to $45^{\circ}$ to the right.

A C1 or SIM 1-configured catheter is recommended for probing the right adrenal gland ( $\bullet$ Fig. 9). The VAN catheter (Boston Scientific) uses SIM 1 configuration with additional 

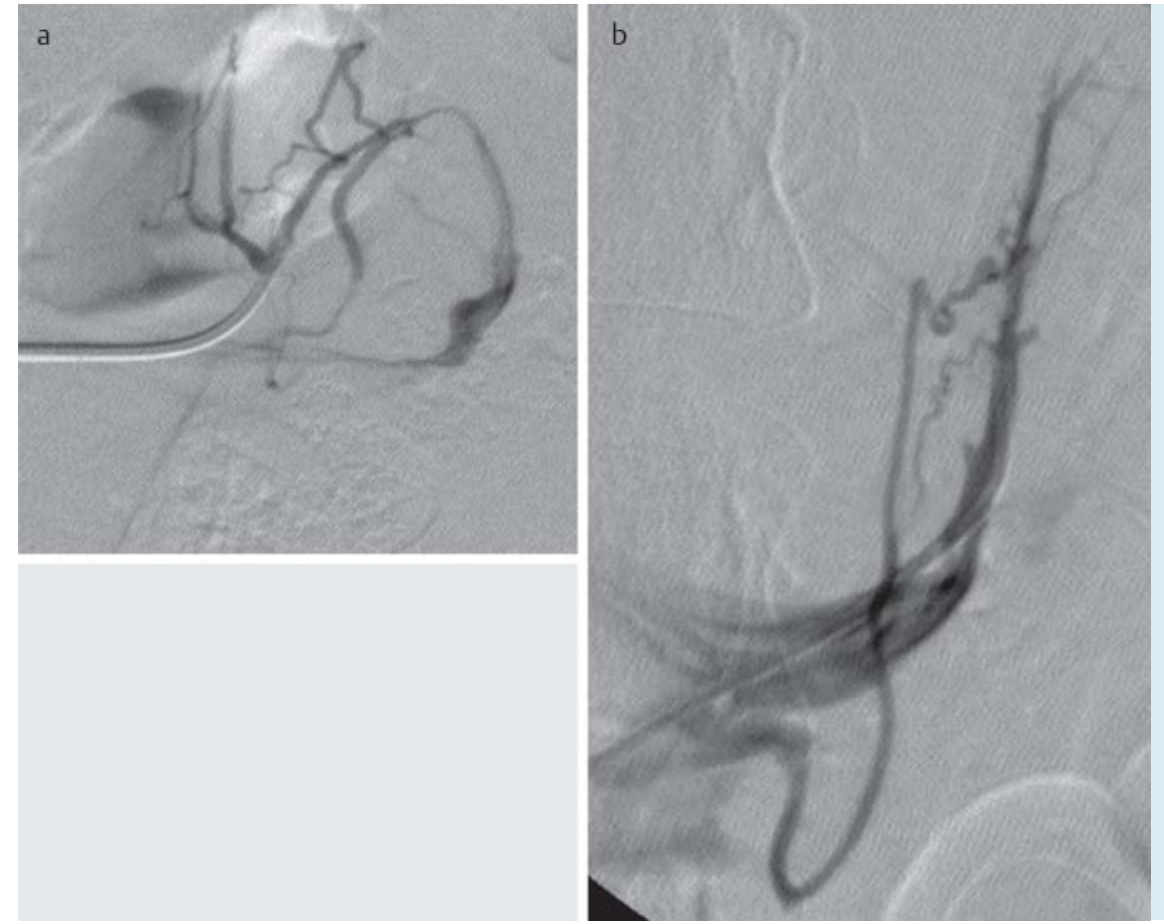

Fig. 7 a Shows a juncture of left-side superficial adrenal veins with the renal vein. $\mathbf{b}$ Shows a juncture with the inferior vena cava below the confluence of the renal vein.
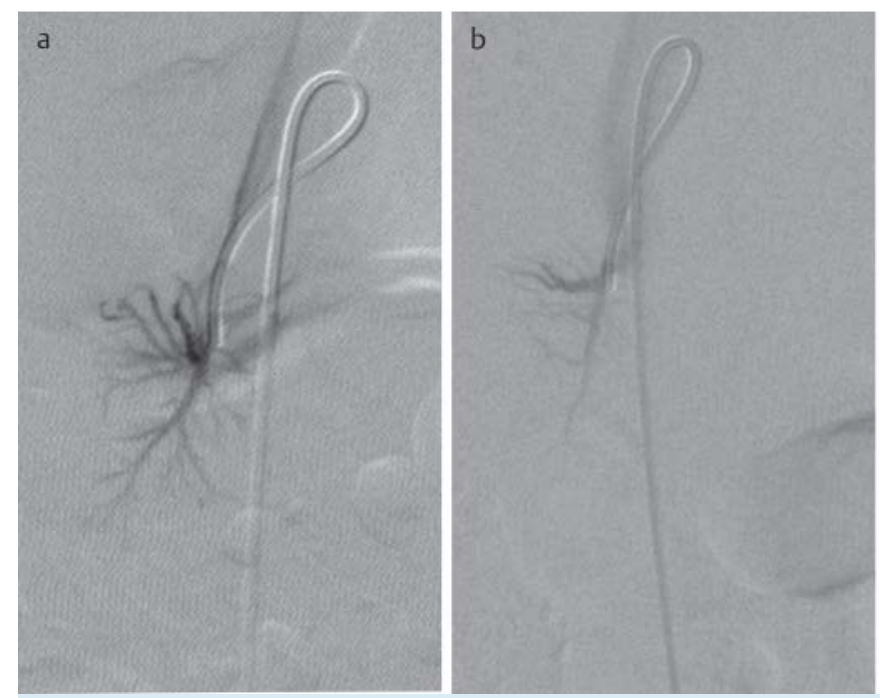

Fig. 8 a Gland-like aspect of the right-side adrenal veins. $\mathbf{b}$ The vessels of the right adrenal gland exhibit a typical delta form; in this case superficial veins are not visible. $\mathbf{c}$ The central adrenal veins are not shown, only a few
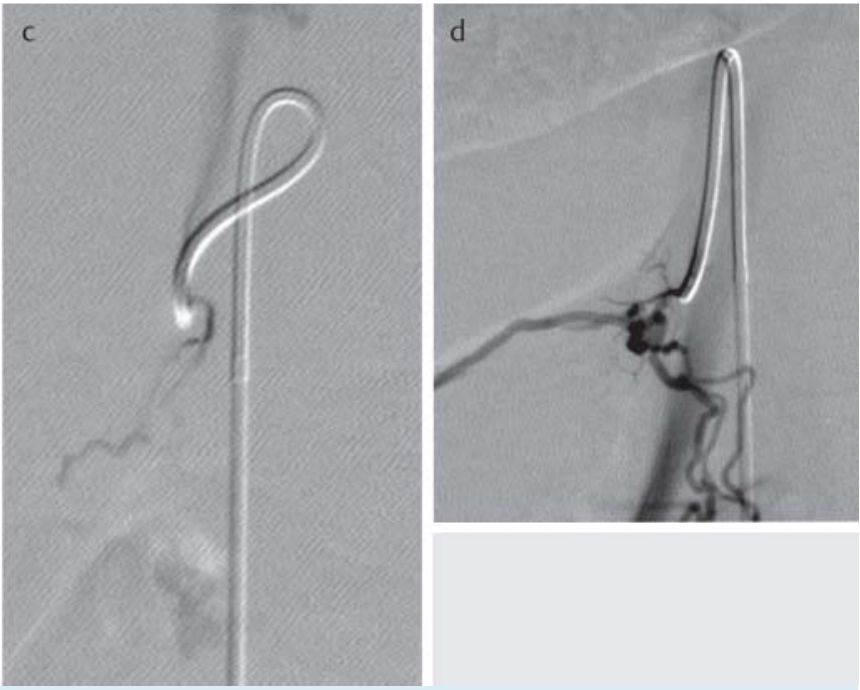

superficial veins are opaque; nevertheless the correct position of the catheter must be determined using these veins. $\mathbf{d}$ The superficial veins exhibit a spider-like configuration. The central veins are only discreetly opaque. lateral perforations near the catheter tip so that blood can easily be sampled when the catheter tip lies against a vein wall. Lateral perforations can also be created manually on the catheter tip using a trocar. The path of the right adrenal vein runs caudally. When a SIM 1 or VAN catheter is used, it is rotated once along the longitudinal axis once it has hooked into the vein ostium so that the catheter tip points caudally rather than dorsally ( $\odot$ Fig. $9 b$ ), thus lying securely in the adrenal vein. For the sake of completeness, the Mikaelsson catheter should be mentioned; this likewise does not possess additional lateral perforations.

In principle the left adrenal vein can be probed using various catheters; in addition to $\mathrm{C} 1$ or $\mathrm{C} 2$ configurations, prob- ing is also possible using a vertebral catheter $[43,44]$. In our opinion, a SIM 2 Glidex catheter provides simpler and faster probing; depending on its configuration in the inferior vena cava or right chamber, if the catheter is withdrawn with the tip pointing left, it automatically lies in the left renal vein, and then upon additional careful withdrawal will rest in the left adrenal vein or the common end section ( $\odot$ Fig. 10). Due to usually large vein caliber, a catheter with a simple end perforation suffices in this case; additional side perforations are not required for the left adrenal vein.

When imaging the veins to confirm the proper catheter position, the contrast medium should be carefully injected and discontinued as soon as a typical blood vessel pattern 

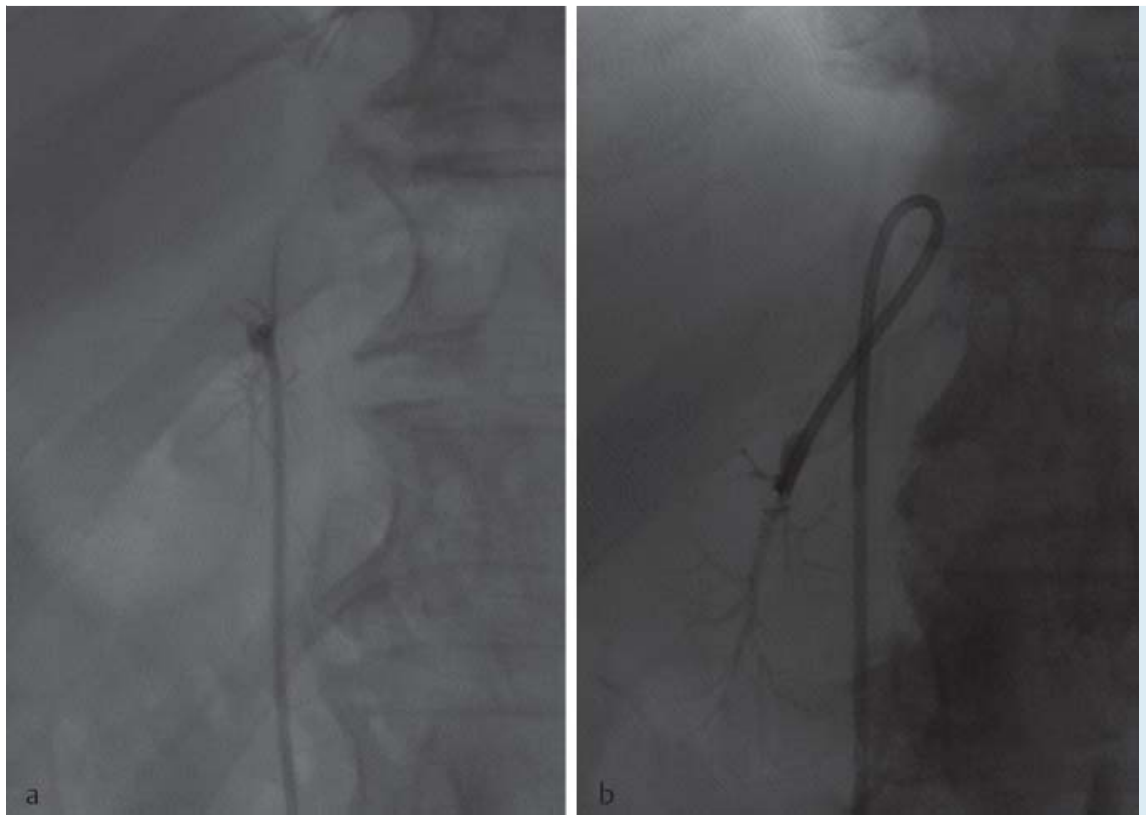

Fig. 9 a Representation of the right-side adrenal veins via $\mathrm{C} 1$ catheter. $\mathbf{b}$ Shows an inserted VAN catheter, its tip pointing caudally, lying in an optimum position in the right adrenal vein.

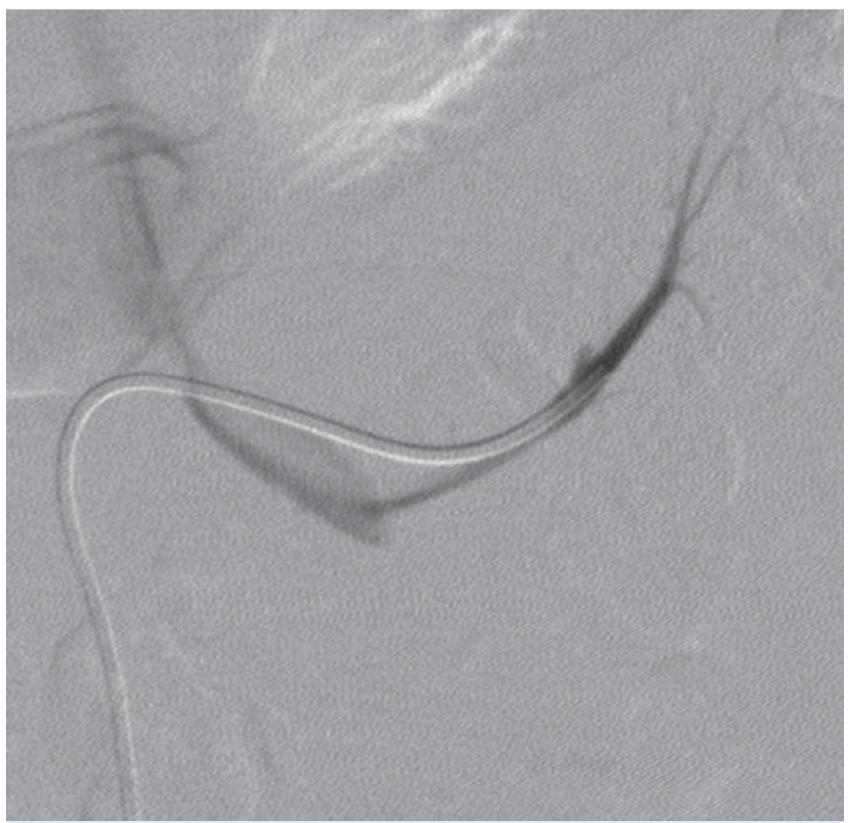

Fig. 10 The SIM 2 catheter is lying in a common venous segment of the phrenic vein and left-side adrenal vein. The veins of the left adrenal gland can be shown in retrograde.

is discerned. A maximum of $3 \mathrm{ml}$ contrast medium should be necessary. Application of too great pressure may perforate adrenal vein branches. Sometimes it is possible to see vessel structure displaced by an existing adenoma ( 0 Fig. 11), but this is not the purpose of using a contrast agent which should be used solely for documenting the proper catheter position. Care should be taken to ensure that the catheter does not lie too deeply in the adrenal vein so that only blood is sampled from a branch of the adrenal gland. This could lead to a false negative result ( $\bullet$ Fig. 12). This pitfall again emphasizes the necessity of administering a contrast medium, as it is the only means to recognize such an error and thus avoid or correct it.

\section{Blood sample evaluation}

First the ratio of cortisol concentration in the adrenal vein (AV) and peripheral vein (PV), e.g. blood from the bleedback prevention valve, is determined [16]; this is designated the selectivity index $\left(\mathrm{SI}=\right.$ Cortisol $_{\mathrm{AV}} /$ Cortisol $\left._{\mathrm{PV}}\right)$. If the $\mathrm{SI}$ is $>2.0$, then this ratio can be used for calculation since the portion of adrenal vein blood sampled is sufficiently high. If the SI $<2.0$, then the blood may not have drained from an adrenal gland, or is blood from an adrenal vein that is contaminated with too much blood from other veins.

In order to prove lateralization, the aldosterone-cortisol ratios for both adrenal veins (AV) are determined in a second step and then compared (aldosterone $\mathrm{AV} \mathrm{Side} 1_{1}: \operatorname{cortisol}_{\mathrm{AV} \text { Side } 1} /$ aldosterone $\left._{\mathrm{AV} \mathrm{Side} 2}: \operatorname{cortisol}_{\mathrm{AV} \mathrm{Side}} 2\right)$. If the ratio is $>3$, then according to the recommendations of the Conn's Registry, there is a probability of APA ( $\bullet$ Table 1 ). If the lateralization index (LI) is $>2$, then there is unilateral disease [45].

If one side cannot be sufficiently cannulated selectively, calculation of the contralateral suppression index (CSI) can sometimes indirectly verify asymmetrical aldosterone secretion [45]. An aldosterone-cortisol ratio in the sample taken from the adrenal vein less than that in the sample of peripheral blood can be interpreted to be an indication of APA on the contralateral side, and in the appropriate clinical context (such as a typical finding in the imaging study) can be assessed as unilateral disease.

\section{Adrenal venous sampling variations \\ $\nabla$}

One variant uses the administration of Synacthen (synthetic signal peptide of ACTH in a $50 \mu \mathrm{g} / \mathrm{h}$ infusion). An advantage of ACTH infusion started prior to the actual catheterization is constant adrenal stimulation which levels circadian variations, thus allowing the examination to be performed later that day or if there are longer interruptions (if, for example several tests must be performed) [46]. There is a further advantage for patients with known contrast agent allergies, 
since dexamethasone can be administered prior to the ACTH infusion. Due to cross-reactivity in immunoassays, administration of prednisolone in such cases is a mistake, however.

Since the ACTH infusion increases the concentration gradient for cortisol and aldosterone from central to peripheral, other threshold values apply to the selectivity and lateralization indices. In this case, an SI $>3$ should be presumed, above which an LI $>4$ would be sufficient indication of unilateral disease [45]. We see problems related to this, since the availability of Synacthen is currently quite limited due to the sale of production rights [47] Further, the distinction between unilateral and bilateral disease can easily be blurred, since normal adrenal tissue responds with raised aldosterone secretion after administration of ACTH [48]. Because

Table 1 Example 1 shows hormone concentrations in the blood obtained by selective adrenal venous sampling together with an example for calculation of the lateralization index, which shows dominant aldosterone secretion from the left adrenal vein. Example 2 shows hormone concentrations obtained by adrenal venous sampling which was formally successful on the left side only. However, calculation of the contralateral suppression index $(<1$ on the left side) indirectly locates excess aldosterone secretion to the right side.

\begin{tabular}{|c|c|c|c|c|}
\hline \multirow[t]{2}{*}{ example 1} & \multicolumn{2}{|l|}{ right } & \multicolumn{2}{|l|}{ left } \\
\hline & NNV & peripheral & NNV & peripheral \\
\hline A in $n g / l$ & 1401 & 439 & 36854 & 429 \\
\hline $\mathrm{F}$ in $\mu \mathrm{g} / \mathrm{dl}$ & 236.8 & 22.9 & 414.0 & 23.6 \\
\hline SI & \multicolumn{2}{|c|}{10.3} & \multicolumn{2}{|c|}{17.5} \\
\hline$A / F$ & 5.9 & - & 89.0 & - \\
\hline LI & \multicolumn{4}{|c|}{ dominant left area, because $89.0 / 5.9>3$} \\
\hline \multirow[t]{2}{*}{ example 2} & \multicolumn{2}{|l|}{ right } & \multicolumn{2}{|l|}{ left } \\
\hline & NNV & peripher & NNV & peripher \\
\hline A in $n g / l$ & 145 & 198 & 382 & 186 \\
\hline $\mathrm{F}$ in $\mu \mathrm{g} / \mathrm{dl}$ & 3.9 & 4.5 & 91.7 & 5.1 \\
\hline SI & \multicolumn{2}{|c|}{0.8} & \multicolumn{2}{|c|}{18.0} \\
\hline$A / F$ & - & - & 4.2 & 36.5 \\
\hline \multirow[t]{2}{*}{ KSI } & \multicolumn{2}{|c|}{-} & \multicolumn{2}{|c|}{0.11} \\
\hline & \multicolumn{4}{|c|}{$\begin{array}{l}\text { the contralateral suppression index in the left side is } \\
\text { assured }<1\end{array}$} \\
\hline
\end{tabular}

A - aldosterone, $\mathrm{F}$ - cortisol, $\mathrm{KSI}$ - contralateral selectivity index, $\mathrm{LI}$ - lateralization index, NNV - adrenal vein, $\mathrm{SI}$ - selectivity index. Explanations on the calculation models are found with the text of the manuscript. of this, we perform AVS without ACTH stimulation at our Center.

Last year a study was published indicating the possibility to investigate the selectivity of AVS with more sensitivity [33]. Based on the assumption of SI $>2.0$ for cortisol, we had an approximate $80 \%$ success rate for bilateral AVS, while the determination of free metanephrine in the plasma indicated that the success rate certainly lay $>90 \%$, and there were even assessable studies for which the SI for cortisol was $<2.0$. The SI for plasma metanephrine during mass spectrometry measurement should be assumed to be above 12 . These threshold values for metanephrine certainly should not apply to immunoassays. Whether increased sensitivity can be utilized to detect lateralized aldosterone excess more sensitively is currently under investigation.

There is an additional possibility of measuring other steroid hormones that might be more specific to aldosteronomas, since adrenal tumors frequently acquire steroid biosynthesis disorders. This ratios could derived from 18-hydroxycorticosterone and aldosterone or cortisol [49], or 18-oxocortisol to cortisol [50] in order to identify an APA with more certainty.

Currently, within the context of the Conn's Registry (www. conn-register.de) and in conjunction with other European centers, research is being conducted to determine whether steroid profiles consisting of $>15$ steroid hormones and intermediary hormones are indicative of an aldosteronoma. In addition, there are studies to determine whether different steroid patterns are caused by various mutations resulting in the development of APAs.

\section{Key statements regarding successful adrenal vein catheterization and current developments \\ $\nabla$}

The diagnostic process undergone by the patient prior to an AVS costs time (multi-stage diagnostics), poses risks (change of medication, functional diagnostics) and is related to a period of disease that frequently long predates diagnosis, and in some cases is fraught with complications. For the patient, the clinical effort is worthwhile particularly if it results in the definite diagnosis of unilateral disease, as this supports the hope for a cure, clinical improvement, or at the least a reduction of the number and dosage of antihy-
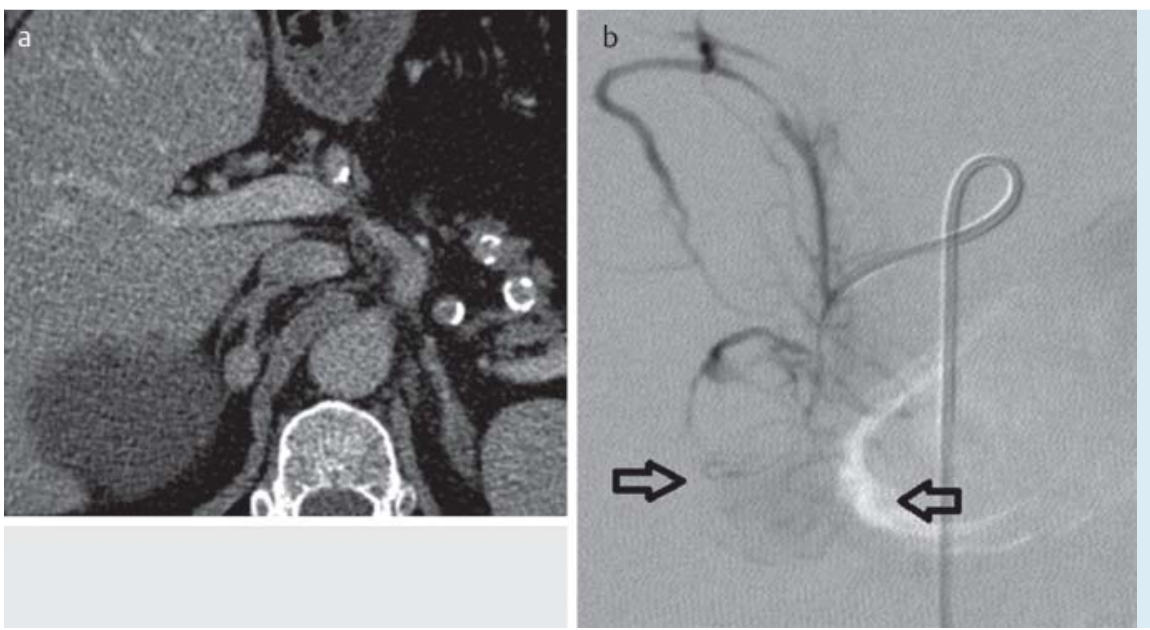

Fig. 11 a Axial $C T$ in the venous phase exhibiting a small right-side adenoma. $\mathbf{b}$ Sometimes an adenoma can be distinguished in the DSA (arrows). 


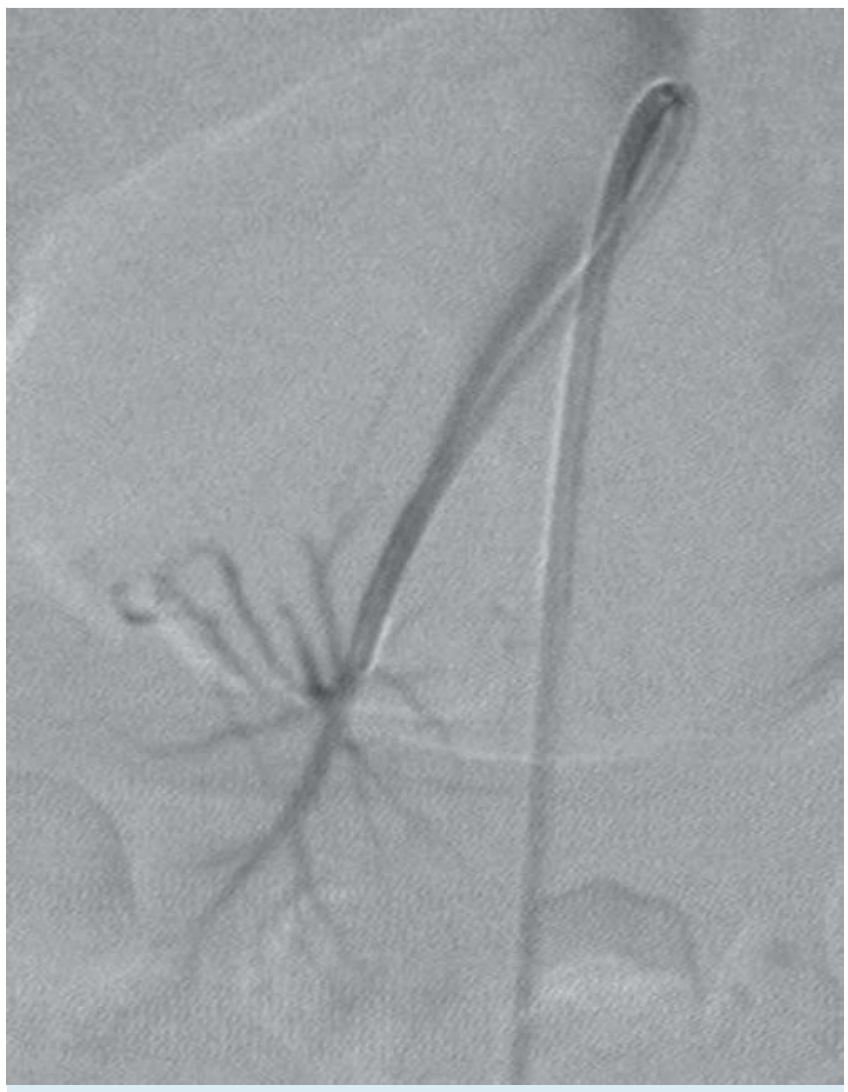

Fig. 12 The VAN catheter is inserted too deeply, preventing sampling of blood from the entire adrenal gland; a false negative result could be the consequence.

pertensive medications as well as related side effects. Consequently several relevant points arise.
- First, the patient should be well informed at the onset of the examination, so that he can deal with potential failure while maintaining motivation to undergo further testing.

- Since the hormones under investigation show strong diurnal fluctuations, the examination should be performed early in the morning after the patient has been reclining for an extended period, as this will level out differences and decrease the specificity of the obtained data $[45,51]$.

- An attempt should be made to obtain sufficient blood from the adrenal veins (approx. $10 \mathrm{ml}$ ), since this may indicate an extremely high level of hormones under normal conditions, and may have to be thinned out multiple times. Attention should also be paid to pre-analysis, since a single questionable hormone value, be it due to improper sample storage, poor assay for these hormone values or ambiguous labeling of a blood sample, can make an entire study worthless.

- It should likewise be taken into account that larger APAs can also secrete relevant quantities of cortisol such that lateralization due to cortisol co-secretion can no longer be identified computationally [13]. Further, the selectivity index on the contralateral side will be erroneously low. Consequently a thorough history should be taken of patients with Conn's syndrome together with a physical examination; in cases of doubt a dexamethasone inhibition test should be performed.

- Selective sampling from the right adrenal vein is best performed with a VAN catheter; time can be saved by probing the left adrenal vein using a SIM 2 catheter with a Glidex tip which is sufficiently effective.

- We recommend careful application of a contrast agent to aid in displaying the position of the catheter; in this way the anatomy and its variants (see above) as well as pitfalls can be detected, and the selective AVS will enjoy a high success rate. A rapid cortisol assay will also provide verification of the result.

- The rapid cortisol assay is the direct determination of cortisol in additionally obtained blood samples (plasma) from the initially cannulated right adrenal vein and from the bleedback prevention valve; it takes 20 to 45 minutes $[52,53]$. During this time the less problematic left side can be probed. If the cortisol level in the blood from the adrenal vein is double that of the peripheral blood sample (SI $>2.0$ ), then a successful assay can be presumed. If it is lower, then it is definitely advisable to take a second or third sample from the right adrenal vein (see above), since the "hit rate" can be thus increased $[52,53]$.

For the sake of completeness we would like to mention that a working group recently demonstrated that an 11C-metomidate-based PET-CT examination is sufficiently sensitive to display even small aldosteronomas and is largely consistent the results of an AVS [54, 55]. Initial efforts to establish similar diagnostic methods in Germany have already been undertaken, but the desired resulting sensitivity will not be available in the foreseeable future [56].

In summary, selective adrenal venous sampling (AVS) currently remains the gold standard for the identification of patients with primary hyperaldosteronism who can profit from adrenalectomy. 


\section{Acknowledgment}

This study was supported by a grant from the Deutsche Forschungsgemeinschaft (WI 3660/1-1, KFO 252/1; HSW).

\section{Literatur}

1 Catena C, Colussi G, Di Fabio A et al. Mineralocorticoid antagonists treatment versus surgery in primary aldosteronism. Horm Metab Res 2010; 42: 440-445

2 Sechi LA, Colussi G, Di Fabio A et al. Cardiovascular and renal damage in primary aldosteronism: outcomes after treatment. Am J Hypertens 2010; 23: $1253-1260$

3 Fourkiotis VG, Vonend O, Diederich S et al. Effectiveness of Eplerenone or Spironolactone treatment in preserving renal function in primary aldosteronism. Eur J Endocrinol 2012; 168: 75-81

4 Fardella CE, Mosso L, Gomez-Sanchez C et al. Primary hyperaldosteronism in essential hypertensives: prevalence, biochemical profile, and molecular biology. J Clin Endocrinol Metab 2000; 85: 1863-1867

5 Mulatero P, Stowasser M, Loh KC et al. Increased diagnosis of primary aldosteronism, including surgically correctable forms, in centers from five continents. J Clin Endocrinol Metab 2004; 89: 1045-1050

6 Rossi GP, Bernini G, Caliumi C et al. A prospective study of the prevalence of primary aldosteronism in 1125 hypertensive patients. J Am Coll Cardiol 2006; 48: 2293-2300

7 Douma S, Petidis K, Doumas $M$ et al. Prevalence of primary hyperaldosteronism in resistant hypertension: a retrospective observational study. Lancet 2008; 371: 1921-1926

8 Quack I, Vonend O, Rump LC. Familial hyperaldosteronism I-III. Horm Metab Res 2010; 42: 424-428

9 Beuschlein F. Regulation of aldosterone secretion: from physiology to disease. Eur J Endocrinol 2013; 168: 85-93

10 Zennaro MC, Rickard AJ, Boulkroun S. Genetics of mineralocorticoid excess: an update for clinicians. Eur J Endocrinol 2013; 169: 15 - 25

11 Scholl UI, Lifton RP. New insights into aldosterone-producing adenomas and hereditary aldosteronism: mutations in the $\mathrm{K}+$ channel KCNJ5. Curr Opin Nephrol Hypertens 2013; 22: 141-147

12 Mansmann G, Lau J, Balk E et al. The clinically inapparent adrenal mass: update in diagnosis and management. Endocr Rev 2004; 25: 309-340

13 Späth M, Korovkin S, Antke C et al. Aldosterone and cortisol co-secreting adrenal tumours - the lost subtype of primary aldosteronism. Eur J Endocrinol 2011; 164: 447-455

14 Milliez P, Girerd X, Plouin PF et al. Evidence for an increased rate of cardiovascular events in patients with primary aldosteronism. J Am Coll Cardiol 2005; 45: $1243-1248$

15 Stowasser M, Sharman J, Leano $R$ et al. Evidence for abnormal left ventricular structure and function in normotensive individuals with familial hyperaldosteronism type I. J Clin Endocrinol Metab 2005; 90 : 5070-5076

16 Funder JW, Carey RM, Fardella C et al. Case detection, diagnosis, and treatment of patients with primary aldosteronism: an endocrine society clinical practice guideline. J Clin Endocrinol Metab 2008; 93: $3266-3281$

17 Diederich S, Willenberg HS, Schirpenbach C et al. Trotz Kombinationstherapie bleibt der Blutdruck oben? Häufiger als vermutet ist ein primärer Hyperaldosteronismus schuld. MMW 2010; 152: 32 - 35

18 Willenberg HS, Gruber M, Eisenhofer G et al. Endokrine Hypertonie Neuigkeiten und jüngste Entwicklungen. Dtsch Med Wochenschr 2012; 137: 627-630

19 Gordon RD. Mineralocorticoid hypertension. Lancet 1994; 344: 240 243

20 Willenberg HS, Vonend $O$, Schott $M$ et al. Comparison of the saline infusion test and the fludrocortisone suppression test in the diagnosis of primary aldosteronism. Horm Metab Res 2012; 44: 527-532

21 Melby JC, Spark RF, Dale SL et al. Diagnosis and localization of aldosterone-producing adenomas by adrenal-vein cateterization. $\mathrm{N}$ Engl J Med 1967; 277: 1050-1056

22 Stowasser M, Gordon R, Rutherford J et al. Diagnosis and management of primary aldosteronism. JRAAS 2001; 2: 156-169

23 Young $W$, Stanson A, Thompson $G$ et al. Role for adrenal venous sampling in primary aldosteronism. Surgery 2004; 136: 1227 - 1235

24 Vonend O, Stegbauer J, Kokulinsky P et al. Vergleich der Bildgebung und seitengetrennten Nebennierenvenenblutentnahme zur Differential- diagnose bei primärem Hyperaldosteronismus. DMW 2007; 132: $2436-2441$

25 Kempers MJ, Lenders JW, van Outheusden L et al. Systematic review: diagnostic procedures to differentiate unilateral from bilateral adrenal abnormality in primary aldosteronism. Ann Intern Med 2009; 151: 329-337

26 Diederich S, Bidlingsmaier M, Quinkler $M$ et al. Diagnostik des primären Hyperaldosteronismus. Med Klinik 2007; 102: 16-21

27 Schirpenbach C, Segmiller F, Diederich S et al. The Diagnosis and Treatment of Primary Hyperaldosteronism in Germany - Results on $555 \mathrm{~Pa}$ tients from the German Conn Registry. Dtsch Arztbl Int 2009; 106: 305-311

28 Lamas C, Alfaro JJ, Lucas T et al. Is unilateral adrenalectomy an alternative treatment for ACTH-independent macronodular adrenal hyperplasia? Long-term follow-up of four cases. Eur J Endocrinol 2002; 146: $237-240$

29 Iacobone M, Albiger N, Scaroni C et al. The role of unilateral adrenalectomy in ACTH-independent macronodular adrenal hyperplasia (AIMAH). World J Surg 2008; 32: 882 - 889

30 Wolf A, Willenberg HS, Cupisti K et al. Adrenal pheochromocytoma with contralateral cortisol-producing adrenal adenoma: diagnosic and therapeutic management. Horm Metab Res 2005; 37: 391 - 395

31 Freel EM, Stanson AW, Thompson GB et al. Adrenal venous sampling for catecholamines: a normal value study. J Clin Endocrinol Metab 2010; 95: $1328-1332$

32 Dekkers T, Deinum J, Schultzekool LJ et al. Plasma metanephrine for assessing the selectivity of adrenal venous sampling. Hypertension 2013; 62: $1152-1157$

33 Nieman LK, Biller BM, Findling JW et al. The diagnosis of Cushing's syndrome: an Endocrine Society Clinical Practice Guideline. J Clin Endocrinol Metab 2008; 93: 1526-1540

34 Quinkler M, Fassnacht $M$, Petersenn $S$ et al. Pheochromocytoma: current diagnostics and treatment. MMW Fortschr Med 2010; 152: $36-38$

35 Levens ED, Whitcomb BW, Csokmay JM et al. Selective venous sampling for androgenproducing ovarian pathology. Clin Endocrinol 2009; 70: $606-614$

36 Stewart PM, Allolio B. Adrenal vein sampling for Primary Aldosteronism: time for a reality check. Clin Endocrinol 2010; 72: 146-148

37 Scholten A, Cisco RM, Vriens MR et al. Variant adrenal venous anatomy in 546 laparoscopic adrenalectomies. JAMA Surg 2013; 148: 378-383

38 Anson BJ, Cauldwell EW, Pick JW et al. The blood supply of the kidneys, suprarenal gland and associated structures. J Urol 1948; 60: 714-737

39 Gagnon $R$. The venous drainage of the human adrenal gland. Rev Can Biol 1956; 14: 350-359

40 Johnstone FR. The suprarenal veins. Am J Surg 1957; 94: 615-620

41 Monkhouse WS, Khalique A. The adrenal and renal veins of man and their connections with azygos and lumbar veins. J Anat 1986; 146 : $105-115$

42 Bookstein IJ. The roles of angiography in adrenal disease. In Abram's angiography. 3rd ed. Boston, Mass: Little, Brown; 1983: 1395-1424

43 Daunt N. Adrenal Vein Sampling: How to make it quick, easy, and successful. Radiographics 2005; 25: $143-158$

44 Palmowski M, Mühlenbruch G, Grouls C et al. Bilaterale selektive Nebennierenvenen-Blutentnahme: Einzelkatheter-Technik mittels eines $4 \mathrm{~F}$ Kobra-Katheters in Standard- und Inversionstechnik. Fortschr Röntgenstr 2011; 187: 167-170

45 Rossi GP, Auchus RJ, Brown M et al. An expert consensus statement on use of adrenal vein sampling for the subtyping of primary aldosteronism. Hypertension 2014; 63: $151-160$

46 Monticone S, Satoh F, Giacchetti G et al. Effect of adrenocorticotropic hormone stimulation during adrenal vein sampling in primary aldosteronism. Hypertension 2012; 59: 840-846

47 Willenberg HS, Ouinkler M, Fassnacht M. Ohne Synacthen gibt es zurzeit keine ACTH-Tests. Vorschläge für Alternativen von der Sektion Nebenniere, Steroide und Hypertonie der Deutschen Geselschaft für Endokrinologie (DGE). Endokrinologie Informationen 2013; 37: 60-62

48 Willenberg HS, Schinner S, Ansurudeen I. New mechanisms to control aldosterone synthesis. Horm Metab Res 2008; 40: 435-441

49 Auchus RJ, Chandler DW, Singeetham S et al. Measurement of 18-hydroxycorticosterone during adrenal vein sampling for primary aldosteronism. J Clin Endocrinol Metab 2007; 92: 2648-2651

50 Nakamura $Y$, Satoh F, Morimoto R et al. 18-oxocortisol measurement in adrenal vein sampling as a biomarker for subclassifying primary aldosteronism. J Clin Endocrinol Metab 2011; 96: 1272-1278 